\title{
Current Knee Osteoarthritis and Non-Surgically Related Falls Injuries Studies: What Prevails, What is Needed, and Why
}

\section{Ray Marks}

Department of Health and Behavior Studies, Program in Health Education, Teachers College, Columbia University, New York, USA.

*Corresponding Author: Prof. Ray Marks, Lecturer, Department of Health and Behavior Studies, Teachers College, Columbia University, New York, USA.

\section{Abstract}

Osteoarthritis, a widespread joint disease, commonly resulting in considerable pain and functional disability among older adults, especially at the knee joint, is often exacerbated by falls and fall injuries, also common among the older population. But what does the research show specifically? This report aimed to update what is known about the risk factors for falls in the context of knee osteoarthritis, and what strategies have been proposed to reduce falls risk among this sizeable older adult patient population. Using key electronic data bases, clinical studies published between January 1,2016 and October 20, 2020 concerning possible explanations for why certain adults with knee osteoarthritis appear to be prone to falling and further injury and disability, along with available falls prevention intervention approaches for this group were sought. Articles fulfilling the eligibility criteria for the review were carefully examined and reported in narrative form. The search results revealed very few recent studies outlining reasons for the extent to which sizeable knee osteoarthritis cases may fall on a single or multiple occasions. Those that do generally fail to employ prospective well-powered research designs, comparable samples, objective or standardized assessment procedures, or well-grounded reasons for the highly varied array of possible falls risk determinants examined. Even when multiple potential falls explanatory risk factors are studied, the diverse results obtained provide little consensus as to why a proportion of adults with knee osteoarthritis are prone to falls, while other are not. At the same time, a substantive body of highly varied approaches for offsetting falls risk among this patient group that have been proposed appear to assume certain falls risk factors are clinically significant, while neglecting others, despite any uniform consensus on this issue. Their current practicality for impacting falls risk is also questionable given the numerous 2020 Covid-19 pandemic-associated practice changes.

Keywords: elderly, falls, fall injuries, falls risk, knee, muscle, osteoarthritis, pain; proprioception, prevention.

\section{INTRODUCTION}

Osteoarthritis, a common disabling progressive joint disease affecting freely moving synovial joints such as the knee, is frequently associated with various degrees of pain plus oftentimes a progressive loss of the ability of the affected person to pursue a high life quality. Among the challenges noted in cases with knee osteoarthritis, the most commonly affected joint, are not only varying degrees of intractable pain, stiffness, and limited mobility, but frequently a strong tendency for one or more affected knee joints to 'give way', along with possible further injury to the knee joints and others, due to ensuing potential injurious falls. At the same time, even if the knee joints are stable, diseases commonly associated with both aging and osteoarthritis such as obesity, diabetes, and cardiovascular diseases, are also all illnesses that can increase the risk of serious falls by the affected individual, for a variety of reasons. Other related disease factors including the strong presence of depression, and lack of sleep, plus possible medications that increase falls risk, further render this patient population potentially highly vulnerable to excess joint damage. As well, neurological disease correlates, such as impaired balance capacity [1], 
Current Knee Osteoarthritis and Non-Surgically Related Falls Injuries Studies: What Prevails, What is Needed, and Why

impaired step kinematics [2] and proprioception, along with a possible decline in muscle strength, and knee stability [3] are additional fall-associated factors that might prevail among older adults diagnosed as having knee osteoarthritis.

But is there a direct linkage between one or more than one of these factors and if so, are current falls prevention as well as osteoarthritis intervention strategies addressing this possible remediable disabler or associated multiple disabling factors. In particular, do current falls prevention programs carefully consider the fact that knee osteoarthritis disease correlates such as poor muscle endurance, muscle timing response deficits, muscle weakness, and muscle wasting, as well as pain, and comorbid diseases are all factors that can arguably induce a high risk for falling, independently or collectively, as well impaired ambulation associated with knee osteoarthritis? [2]. Since falling accounts for significant numbers of hospital and long-term care admissions in older adults [3], but it may be that many adults in their advancing years who are also experiencing a decline in their functional ability due to knee osteoarthritis are at an even greater risk, should more emphasis on this possible extraneous health burden be forthcoming? Moreover, since those adults who are healthy and fall and fracture a hip or another bone, may also develop osteoarthritis that is challenging to treat, and can in turn produce a cycle of persistent or recurrent fallassociated injuries, should more prominence be given to this topic in the related literature?.

In a previous report [4], we noted that there appears to be a great need to both understand the linkages that may lead knee osteoarthritis cases to incur worse, rather than better health outcomes. In particular, it was noted that falls may play a large role in this regard, even if not currently key therapeutic targets, but that preventive strategies that do exist, may be either too general, or may not duly consider the impact of the 2020 COVID-19 pandemic on health access and delivery.

One question posed in that report was whether any consensus exists as to the relevance of any observed osteoarthritis-falls linkage, as the literature had been ambiguous as well as limited in scope on this point to date. Another was what would be needed to further our understanding of these key risk factors such as falls injuries that might markedly lower life quality among the elderly knee osteoarthritis cases.

\section{RATIONALE}

Both knee osteoarthritis as well as falls injuries, which have an independently high incidence among older adults [5-8], as well as a collective prevalence, currently pose an enormous challenge to many aging individuals, worldwide, as well as tremendous challenges to health providers, plus immense hospital and societal costs. At the same time, what produces falls that can impact knee osteoarthritis outcomes negatively is relatively unknown. Since outcomes for knee osteoarthritis sufferers' who fall are significantly worse than those who don't, as well as healthy age matched cohorts [6], it appears a better understanding of what specific variables might be amenable to intervention in at risk individuals, and achieving evidence based guidelines in this respect would undoubtedly be highly advantageous in the context of primary, as well as secondary and tertiary preventive efforts $[6,8]$. Moreover, since falling, as well as excess pain and disability that can arise due to falls are paramount among the important causes of premature mortality and morbidity in advanced age, the assessment of risk factors for falling and effective strategies to prevent these appear of specific salience to consider in the context of primary disabling knee osteoarthritis [8].

\section{Materials AND Methods}

To obtain the desired data for the present review, the PUBMED electronic data base was initially used to access appropriate scientific publications listed when applying the key terms: "knee osteoarthritis and falls", "knee osteoarthritis and falls risk", "knee osteoarthritis and falls prevention", and others outlined in Table 1. As well, the Web of Science Consolidated, and Scopus data bases were reviewed for additional data. Articles published in the English language as full reports and pertinent to the current discussion, with the exception of falls relative to older adults in general, and/or total joint replacement surgery prospective follow up studies were sought. Excluded too were articles that did not discuss knee osteoarthritis per se, for example those that discussed falls and hip osteoarthritis, articles on the perception of possible falls, the fear of falling, or falls in healthy older adults, or were study proposals. Available data extending from January 1 
Current Knee Osteoarthritis and Non-Surgically Related Falls Injuries Studies: What Prevails, What is Needed, and Why

2016-October 20,2020, a time frame not well studied, were specifically examined. No ethics approval was required, as this narrative review presents data that does not violate human rights, as documented in The Helsinki Declaration. Those articles of potential relevance were first screened for salience, and if deemed pertinent in the author's view to the present topic, downloaded and scrutinized further. The review material was then categorized into general versus specific topic reports, carefully examined and summarized and reported in narrative form, given the lack of any uniform focus or diagnostic descriptions in most studies. All forms of clinical study as well as review articles were deemed acceptable, and stressed the topic of falls risk factors in the context of definitive knee osteoarthritis, rather than the role of falls in causing possible knee osteoarthritis. Post-surgical falls studies were excluded, as these may differ in nature from the natural history of knee osteoarthritis as experienced by most sufferers. Intervention study approaches were noted and reviewed only in the context of whether these appeared to adequately 'map' the proposed falls risk indicators reported as having a role in this disease, that is if their recommended mode of intervention appeared to match salient falls predictors among knee osteoarthritis cohorts. Their practicality was also briefly reviewed in light of changes in health delivery post COVID-19.

Each falls related risk factor article selected was reviewed with regard to its methodological approach, study size and sample features, the main findings of the study, the study conclusions, and possible limitations. Each topic advocated for preventing falls in cases with knee osteoarthritis was briefly noted, along with its efficacy, and relationship to the body of falls risk factor evidence, and its practicality in the field. Implications for research and practice based on the results of the search were included along with a discussion of what is needed to advance practice in this realm. PUBMED was selected as the key electronic data source of information given its widespread data repository and effective method of accessing relevant data. For a concise summary of prior work, the review by Manlapaz et al. [9] is recommended.

\section{RESULTS}

Table1. Initial PUBMED search terms and numbers of related citations in past 5 years (2016-2020)

\begin{tabular}{|c|c|}
\hline SEARCH TERM & Citation \# \\
\hline Knee osteoarthritis AND falls risk factors & 41 \\
\hline Knee osteoarthritis AND falls prevention & 40 \\
\hline Knee osteoarthritis AND falls & 131 \\
\hline Knee osteoarthritis AND falls OR falls injuries & 6,337 \\
\hline Knee osteoarthritis & 14,285 \\
\hline
\end{tabular}

There were 122 citations matching the key search term "falls risk factors and knee osteoarthritis" in the Web of Science data base, but only 10 were

relevant or unique. In Scopus, only 61 articles on this aforementioned theme were observed, and only 2 were unique or relevant (see Figure 1 below).

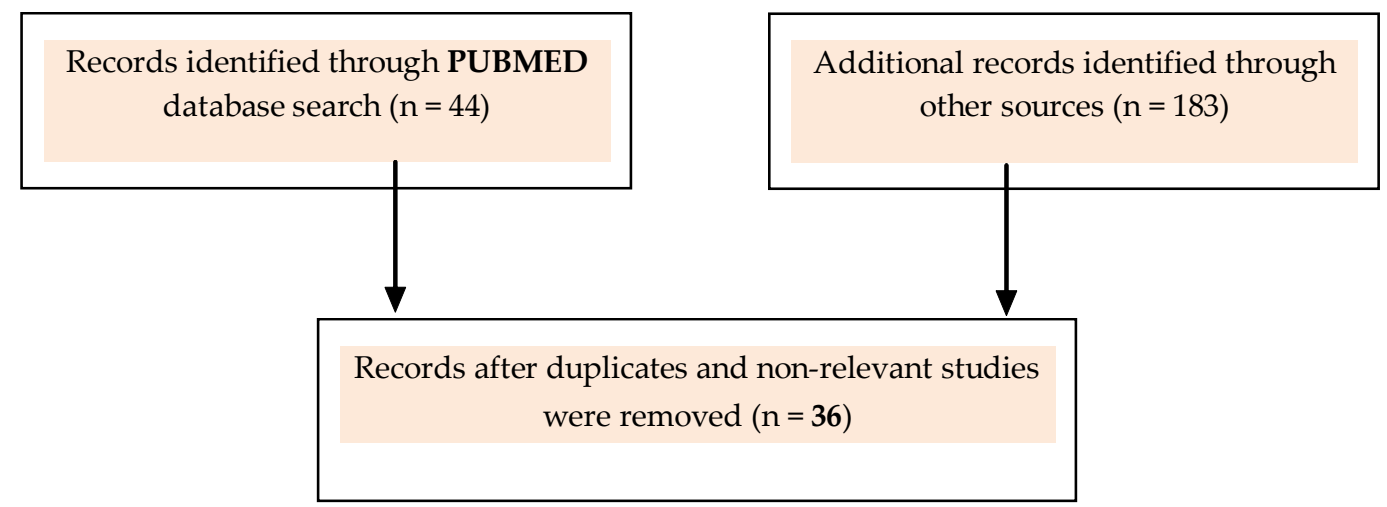

Figure1. Outcome of key search term "knee osteoarthritis AND falls risk factors", 2016-2020 
Current Knee Osteoarthritis and Non-Surgically Related Falls Injuries Studies: What Prevails, What is Needed, and Why

Study Results

\section{General Study Characteristics}

Of the 36 key studies on falls risk factors for knee osteoarthritis published since January 1, 2016, and meeting criterion for this review, most were crosssectional studies, or systematic reviews. Several of these that were prospective in nature only assessed end-stage knee osteoarthritis and post-surgical falls outcomes, rather than the natural evolution of falls and their possible determinants, or analyzed secondary data from multiple sites retrospectively. Few examined specific possible risk factors using objectively derived data, or mechanisms to account for the observed falls rates in knee osteoarthritis cases, and most notably omitted were potentially a variety of salient biomechanical factors as possible determinants. In other cases, only recurrent falls indicators, rather than a single sporadic falls event were discussed, and although some examined whether joint status affects falls risk, this was not generally the case. A number discussed interventions to offset falls, without any actual strong evidence base, and as a whole various, rather than any uniform falls-associated measures or procedures were evidenced in this regard.

\section{Sample of Specific Empiricall Observations}

As outlined in the systematic review by Manlapaz et al. [9] who undertook a risk factor analysis that covered the current falls risk factor topic up until July 2016, very few studies listed in any data base on this topic met criteria for this updated review on falls risk factors in knee osteoarthritis cases. Indeed, of the 4382 studies related to falls and knee osteoarthritis that appeared in the data base reviewed by Manlapaz et al. [9], this group was only able to find 11 salient studies to review specifically. In this regard, this group noted the risk factors for falling among persons with knee osteoarthritis to mostly fall into biomechanical and neuromuscular categories and others including impaired balance, muscle weakness, the presence of comorbidities, higher numbers of symptomatic joints, and to a lesser degree pain. It was concluded that despite the limited data set and possible problems with studies, these data could prove helpful in efforts to prevent falls in this group.

In another systematic review that focused on knee and hip total arthroplasty cases with osteoarthritis, di Laura Frattura et al. [10] who examined 11 articles and that involved 1237 patients to uncover the prevalence of falls among end-stage knee osteoarthritis cases awaiting total joint replacement surgery, found a pre-operative fall prevalence ranging from $23-63 \%$, suggesting falls may not be a problem for some severely disabled knee osteoarthritis cases, but may be a greater problem for others. There was only 'moderate' evidence for the role of clinical status based on clinical scales in this regard, and conflicting evidence for sex, prior falls history, age, kyphosis, muscle weakness, fear of falling, depression, balance, and impaired gait. The authors noted that although possible falls risk factors were identified to some degree, no studies demonstrating the possible use of strategies to impact falling among similar cohorts could be located. All data published in this review were deemed acceptable, however.

In a more recent four year long longitudinal analysis of 4231 study participants who ranged in age from 45-79 years of age at baseline, Lo-Ciganic et al. [11] focused on examining possible factors affecting recurrent falls incidence among knee osteoarthritis cases or those deemed at risk for this condition whose data were analyzed with regression analyses to tease out the relative influence of several attributes. These included: opioid and antidepressant medication usage, the use of other pain medications, nutraceuticals, or no analgesics. Unfortunately, when examining recurrent falls risk in the following year, and in adjusting for demographics and health status/behavior factors, results were not conclusive or robust. They did show however, that opioid use may be a possible recurrent falls risk factor, as may antidepressant usage. No other factors were studied however, for example biomechanical factors, and the dosages and/or reasons explaining the medication usages-falls linkages specifically for those with the disease were not clear. The data emanating from 2004-2006 from specific multi centre data of those with non confirmed knee osteoarthritis, as well as inclusion of only those with complete data sets, may not represent the clinical situation at all adequately in 2020. The use of self-reports, phone interviews, and nature of the medication checks must also be deemed problematic, and among samples, where only 38.8 percent were over age 65 years. As well, falls risk factors versus recurrent falls risk determinants may not coincide or concur. 
Current Knee Osteoarthritis and Non-Surgically Related Falls Injuries Studies: What Prevails, What is Needed, and Why

In a further multi center osteoarthritis study of recurrent falls among knee osteoarthritis cases or adults deemed at risk for this condition, who were between the ages of 50-79 years, Nevitt et al. [12] who examined knee instability as a possible risk factor in a cohort of 1842 cases at high risk for falling 60 months after baseline, ascertained their data by asking the participants whether their knee had 'given way' in the past three month period, and if so, whether they had subsequently fallen. The authors then analyzed the reported falls and fall-related injuries that had occurred in the past 12 months, as well as analyzing the balance confidence perceptions of the participants at 60 and 84 months. At 60 months, it was noted that $16.8 \%$ of the cohort reported 'buckling' of the knee and at 84 months $14.1 \%$ reported they had fallen more than once. Those who experienced buckling at 60 months had a 1.6-2.5-fold greater odds of falling more than once. Those who reported falling when their knee buckled at baseline had a 4.5-fold increased odds of incurring a recurrent fall within 2 years, along with significant injuries. Actual measures of knee instability were hard to discern however, and the reported data were largely subjective self-reports, rather than actual objective measures. The proportion of non fallers with actual instability or buckling signs and what accounted for this was not clear. Moreover, the possible actual loss of postural control as a falls risk factor, plus the role of age, pain, pain medications, depression, knee joint status, knee muscle strength, and comorbidities among this group, plus the possible mediating role of symptom severity [13] was not truly apparent. As well, most cases were non fallers, rather than fallers, but since physical activity was not adjusted for, and knee instability was based on selfassessments, this group may simply have been less exposed to falling due to excess pain, fears or use of assistive devices. They may also have had challenges in accurately interpreting the idea of knee buckling or recurrent falls and slips or recalling these events, leading to miss classification.

In another study examining falls risk factors among knee osteoarthritis cases, van Schoor et al. [14] examined falls risk as reported by participants prior to undergoing total hip or total knee replacement surgery. This was a prospective study with a one year followup that was said to use pre-harmonized data from five
European population-based cohort studies (ages 65$85, n=2535$ ). Over this time period, the researchers reported finding that $27.7 \%$ of participants fell once or more and $9.8 \%$ fell at least twice. After adjusting for confounders, the clinical data appeared to correlate with the incidence of falling more than once, but after adjusting the data for confounders, physical activity participation or performance was not found to be a mediating factor, contrary to opioid and analgesic usage, which was found to be a mediating factor for recurrent falls. Other variables, such as neuromuscular variables and pain were not directly assessed.

Ofori-Asenso et al. [15], another group who used data from the Osteoarthritis Initiative, aimed in their study to determine the prevalence and correlates of self-reported falls among 1019 middle aged cases 45-64 years of age with knee or hip osteoarthritis. In this regard, these researchers found a higher likelihood of falls among women, and those with a greater incidence of comorbid conditions, as well as those with a higher depression score, those who were Caucasian and those who had a higher educational level of attainment. Opioid usage was also mentioned as a possible factor. This cross-sectional study focused however on cases with osteoarthritis of the lower limb, in general, not knee osteoarthritis, in particular. Rather than cognitive factors, however, another study revealed greater evidence of walking difficulty and low back pain as strong falls risk indicators in severely disabled osteoarthritis cases [16]. Although Kuroglu et al. [7] found falls as well as fear of falling to impact daily activities in those with knee osteoarthritis, they did not clearly implicate the factors underpinning this, such as balance, a factor supported as relevant by Anderson et al. [17], Levinger et al. [1] and Pater et al. [2] .

Other factors that were not examined were the possible role of low falls efficacy, worse function, greater pain catastrophizing, and worse mental health as per observations of Hill et al. [18]. As well, omitted from substantive discussion were factors such as gender, pain and WOMAC scores [19], depression severity, anxiety, symptom severity, narcotic use, age, and activity participation [20,21]. A summary of the various observations made in this regard, notwithstanding their limitations is presented in Table 2. 
Current Knee Osteoarthritis and Non-Surgically Related Falls Injuries Studies: What Prevails, What is Needed, and Why

Table 2. Selected features of representative studies examining falls risk factors among cases with knee osteoarthritis as published between January 12016 and October 30, 2020

\begin{tabular}{|c|c|c|c|}
\hline Authors & Sample & Results & Conclusion \\
\hline Aljahani et al. [16] & $\begin{array}{c}259 \text { total knee arthroplasty cases } \\
\text { awaiting surgery }\end{array}$ & $\begin{array}{l}\text { For each } 1 \text { point increase in low } \\
\text { back pain using a 1-10 scale, a } \\
\text { greater falls risk was identified } \\
\text { Those who walked further in } 6 \text { mi- } \\
\text { nutes showed a reduced falls risk }\end{array}$ & $\begin{array}{l}\text { Falls in end stage knee osteoarthritis } \\
\text { are due to low back pain and limited } \\
\text { walking endurance } \\
\text { Future falls preventive studies for this } \\
\text { group should test these premises }\end{array}$ \\
\hline Tasci Bozbaz et al. [8] & $\begin{array}{l}50 \text { adults with knee osteoarthri- } \\
\text { tis, } 50 \text { healthy controls }\end{array}$ & $\begin{array}{l}\text { The median falling index was } 52 \text { in } \\
\text { knee osteoarthritis group, compa- } \\
\text { red to } 31 \text { in the control group } \\
\text { Falling was predicted by disease } \\
\text { status } \\
\text { Pain and functional status did not } \\
\text { appear to influence the risk of } \\
\text { falling }\end{array}$ & $\begin{array}{l}\text { Primary knee osteoarthritis is a risk } \\
\text { factor for falling } \\
\text { Medical attention, proprioception/ba- } \\
\text { lance/gait training, muscle strengthe- } \\
\text { ning, and home safety arrangements } \\
\text { may reduce falls risk in those with } \\
\text { knee osteoarthritis }\end{array}$ \\
\hline Levinger et al. [1] & $\begin{array}{l}\text { Lab simulation study of knee } \\
\text { osteoarthritis cases and } \\
\text { asymptomatic controls in ability } \\
\text { to recover balance during: nor- } \\
\text { mal obstacle clearance, and dual } \\
\text { cognitive dual tasks } \\
\text { Spatiotemporal parameters, } \\
\text { lower limb joint kinematics and } \\
\text { recovery kinetics were compa- } \\
\text { red between the limbs of the } \\
\text { two groups and across the three } \\
\text { tasks }\end{array}$ & $\begin{array}{l}\text { The osteoarthritis group exhibited } \\
\text { slower spatio-temporal features } \\
\text { and several kinetic angular and } \\
\text { muscle function differences } \\
\text { Cognitive dual task results differed } \\
\text { from those of the physical dual } \\
\text { task condition }\end{array}$ & $\begin{array}{l}\text { When asked to simulate a forward fall, } \\
\text { knee osteoarthritis cases have greater } \\
\text { difficulty in absorbing the impact and } \\
\text { slowing down forward body momen- } \\
\text { tum during step recovery } \\
\text { Moreover, as the task increased in } \\
\text { complexity, worse dynamic postural } \\
\text { control was demonstrated }\end{array}$ \\
\hline *Lo-Ciganic et al. [11] & $\begin{array}{l}\text { This was a } 4 \text { year follow up of } \\
4231 \text { cases ages } 45-79 \text { years of } \\
\text { age embedded in the Osteoar- } \\
\text { thritis Initiative }\end{array}$ & $\begin{array}{l}\text { Approximately } 15 \% \text { of cases expe- } \\
\text { rienced recurrent falls }\end{array}$ & $\begin{array}{l}\text { Those with knee osteoarthritis or } \\
\text { those at risk for knee osteoarthritis } \\
\text { who used opioids or antidepressants } \\
\text { appeared more susceptible to incur- } \\
\text { ring multiple falls } \\
\text { Caution is advised for adults with } \\
\text { osteoarthritis who consistently use } \\
\text { opioids and/or antidepressants }\end{array}$ \\
\hline Mat et al. [21] & $\begin{array}{l}\text { Cross-sectional case-control } \\
\text { study of } 389 \text { participants [ } 229 \\
\text { fallers-who self-reported } 2 \text { or } \\
\text { more falls in past year or one } \\
\text { injurious fall at a hospital; } 160 \\
\text { non-fallers from community], } \\
\text { age ( } \geq 65 \text { years) were studied } \\
\text { to examine fear of falling and } \\
\text { psychological factors as falls } \\
\text { mediators relative to clinical } \\
\text { or radiological osteoarthritis } \\
\text { symptom severity }\end{array}$ & $\begin{array}{l}\text { Individuals with radiological } \\
\text { osteoarthritis and 'mild' overall } \\
\text { symptoms had a reduced risk of } \\
\text { falls compared to asymptomatic } \\
\text { cases } \\
\text { Those with clinically defined } \\
\text { 'severe' disease and overall } \\
\text { symptoms had an increased risk of } \\
\text { falls compared to those with 'mild' } \\
\text { osteoarthritis }\end{array}$ & $\begin{array}{l}\text { Fallers report higher rates of fear of } \\
\text { falling and depression than non- } \\
\text { fallers } \\
\text { Radiological osteoarthritis, and mild } \\
\text { symptoms appears protective against } \\
\text { falls } \\
\text { Having severe clinical osteoarthritis } \\
\text { increases falls risk compared to those } \\
\text { with mild symptoms } \\
\text { Both relationships were not mediated } \\
\text { by physical limitations }\end{array}$ \\
\hline
\end{tabular}


Current Knee Osteoarthritis and Non-Surgically Related Falls Injuries Studies: What Prevails, What is Needed, and Why

\begin{tabular}{|c|c|c|c|}
\hline Nevitt et al. [12] & $\begin{array}{l}\text { Men and women with knee } \\
\text { osteoarthritis examined } 60 \\
\text { months after baseline }\end{array}$ & $\begin{array}{l}\text { Subjects were queried about knee } \\
\text { instability and buckling }\end{array}$ & $\begin{array}{l}\text { Among } 1842 \text { subjects, } 16.8 \% \text { expe- } \\
\text { rienced 'buckling' of the leg at } 60 \\
\text { months } \\
\text { 14.1\% who had experienced 'buck- } \\
\text { ling', experienced } 2 \text { or more falls at } 84 \\
\text { months } \\
\text { Those who fell due to buckling at } \\
\text { baseline had a 2-4.5 increased odds of } \\
\text { incurring recurrent falls and injuries } \\
\text { over } 2 \text { years and were more likely to } \\
\text { have poor balance }\end{array}$ \\
\hline *Smith et al. [6] & $\begin{array}{l}552 \text { individuals with hip } \\
\text { osteoarthritis were compared } \\
\text { to } 4244 \text { individuals without hip } \\
\text { osteoarthritis; } 1350 \text { individuals } \\
\text { with knee osteoarthritis were } \\
\text { compared to } 3445 \text { individuals } \\
\text { without knee osteoarthritis }\end{array}$ & $\begin{array}{l}\text { People with knee osteoarthritis } \\
\text { had a } 54 \% \text { greater chance of expe- } \\
\text { riencing a fall compared to those } \\
\text { without; } \\
\text { those with hip osteoarthritis had a } \\
52 \% \text { greater chance } \\
\text { Those diagnosed with knee + hip } \\
\text { osteoarthritis had an } 80 \% \text { greater } \\
\text { chance of experiencing a fracture }\end{array}$ & $\begin{array}{l}\text { There is an increased risk of falls and } \\
\text { fractures in early-diagnosed knee and } \\
\text { hip osteoarthritis compared to those } \\
\text { without osteoarthritis } \\
\text { International guidelines on the ma- } \\
\text { nagement of hip and knee osteoar- } \\
\text { thritis should consider the impor- } \\
\text { tance of the management of falls risk }\end{array}$ \\
\hline *Soh et al. [22] & $\begin{array}{l}4796 \text { participants, } 2270 \text { dia- } \\
\text { gnosed as having knee and/or } \\
\text { hip osteoarthritis }\end{array}$ & $\begin{array}{l}\text { 72\% participants with osteoar- } \\
\text { thritis reported falling and } 17 \% \\
\text { reported fractures } \\
\text { Personal factors were strongest } \\
\text { predictors of falls and fractures } \\
\text { A self-reported history of falls } \\
\text { was a significant predictor of both } \\
\text { increased falls + fracture risk }\end{array}$ & $\begin{array}{l}\text { Personal factors are more likely } \\
\text { to predict falls and fractures than } \\
\text { impairments } \\
\text { It is important to assess osteoar- } \\
\text { thritis patients' past falls + medical } \\
\text { history }\end{array}$ \\
\hline
\end{tabular}

*Data source=0steoarthritis Initiative (https://nda.nih.gov/oai/)

In short, the documented studies listed above along with samples depicted in Table 2 show most studies concerning the association between non-surgically treated knee osteoarthritis and falls injuries to be based on weak evidence of observational, preclinical, or retrospective studies. In addition, among these, the specific impact of disease severity and duration, numbers of affected joints, muscle strength, balance, walking ability, and proprioception [23], plus an array of possible cognitive factors, which intuitively would appear salient to assess, do not appear to have been duly assessed in most studies, regardless of study approach. As a result, which of the numerous possible factors measured to date are of high clinical relevance in terms of explaining falls incidence and prevalence in some studies listed above and shown in Table 2, as well as prior studies, appears impossible to establish at present. The cause effect associations that might exist and are especially of great import, also remain in question.

\section{Discussion}

The impact of knee osteoarthritis on the risk of falling and sustaining worse outcomes than anticipated is fairly well established as a serious problem among sizeable numbers of cases. However, even though more than 30 years of study in this regard prevail, an extensive search of the PUBMED and other key data bases reviewed in 2020 reveals only a very small percentage of all osteoarthritis papers that refer to knee osteoarthritis that discuss falls or examine the reasons why this group may be prone to falling. Moreover, even when the data sources examined give the impression that they house a reasonable number of relevant papers on the present topic of interest, most fail to align with the present quest to simply outline falls risk factors, and their preventive solutions. That is, despite numerous attempts to use varying key words, consistent with a past analysis, that only revealed 11 studies, out of more than 4000 possible items, presently only 36 somewhat relevant papers 
Current Knee Osteoarthritis and Non-Surgically Related Falls Injuries Studies: What Prevails, What is Needed, and Why

published since 2016 could be located. As well, of the many topics that appeared initially to have potential to inform this review, most were clearly irrelevant to this present discussion for various reasons, for example, these included studies of post arthroplasty cases, completely unrelated studies, studies of healthy adults, laboratory simulation studies, and retrospective and computational studies. Surprising too was the very limited number of longitudinal clinical studies other than post surgical studies or intervention studies on this general topic.

At the same time, diverse somewhat subjective modes of assessing falls, falling, and recurrent falls themselves, that relied on memory, or the given definition of falls, plus the differing definitions of knee osteoarthritis, among other factors, such as disease duration, and extent, the role of prior surgery, corticosteroid injections and others, current medications, sleep factors, and comorbid disease profiles truly precluded any meaningful analysis, and an attempt to summate these data effectively in our opinion.

According to some of this data, for example, although one can predict with reasonable certainty that older adults with knee osteoarthritis may be more prone to falling or falls than healthy age-matched adults, $\mathrm{Ng}$ and Tan [24] who conducted a review of the existing literature in 2013 found limited evidence in support of this assumption. On the contrary, they argued that that osteoarthritis may actually be protective against falls and related fractures. However, it was unclear why joint arthroplasty surgery appeared to increase the risk of falls in individuals with osteoarthritis according to their observations.

In 2018, meantime, di Laura Frattura et al. [10] who examined falls risk factors in another systematic review, and among knee joint arthroplasty cases, found pre-operative falls prevalence to range from $23-63 \%$, while post-operative values ranged from $12-38 \%$, suggesting at least some knee osteoarthritis cases, if not all are vulnerable to falls. Moderate evidence indicated no pre operative influence of clinical scales, body mass or joint range of motion differences between "fallers" and "non-fallers", however, suggesting these factors do not determine falls risk. Conflicting evidence was found however, for the variables of sex, history of previous falls, age, kyphosis, muscle weakness, fear of falling, depression, balance, and gait impairment. This systematic review may nothave examined the entire spectrum of available studies, or alternately, it was what was studied that determined the overall findings, and these data were clearly limited or confusing. For example, Barbour et al. [5], who conducted a community based study, showed knee osteoarthritis was indeed independently associated with an increased risk of injurious falls, but that this was only true for older men, not for older women. Riddle et al. [25] however, found the reverse to be true.

The possible nature of this problem is also inconsistent among the published works. For example, Smith et al. [6] reported cases with knee osteoarthritis to have a $54 \%$ greater chance of experiencing a fall compared to those without the disease, but Aljehani et al. [16] showed that only about $25 \%$ of patients with endstage knee osteoarthritis may report falling.

Why this occurs, remains unclear, for example, van Schoor et al. [14] indicate a role for opioid and analgesic usage to mediate the associations between clinical osteoarthritis and (recurrent) falls, while physical performance and physical activity did not. Lo-Ciganic et al. [11] similarly noted participants with or at risk of knee osteoarthritis who used opioids and antidepressants with/without other analgesics/ nutraceuticals may have an increased risk of recurrent falls after adjusting for potential confounders, but the combined role of physical as well as psychological correlates that may be implicated in falling, especially among the older osteoarthritis adult, as outlined by Byun et al. [26] was not truly examined or discussed. As well the role of fear of falling as a possible independent falls predictor was not mentioned as implied by comparable research by Byun et al. [26]

Tsonga et al. [27] who investigated the role of the history of falls including their frequency, mechanism and location, among a cohort of older adults aged 65 years and older suffering from severe knee osteoarthritis found almost $90 \%$ of these falls had occurred during walking, and $41 \%$ of the cases studied reported stumbling episodes in the past year. Thirty percent of cases experienced a falls-based injury. 
Current Knee Osteoarthritis and Non-Surgically Related Falls Injuries Studies: What Prevails, What is Needed, and Why

Unsurprisingly, since recovery step kinematics may be impaired in knee osteoarthritis, especially if not intervened upon [10], adults with knee osteoarthritis mayyet experience repeated falls [28]. However, rather than implicating any biomechanical explanation for this finding, Iilima et al. [28] attributed their finding of the occurrence of multiple falls in their sample to the presence of mild-moderate low back pain, and possible opioid usage that impairs reflex responses. Nevitt et al. [12] who examined whether knee instability contributes to the increased risk of falls and fractures observed in persons with knee osteoarthritis felt however, that it was those knee osteoarthritis who experienced 'buckling' who seemed more likely than not to incur recurrent falls, significant fall injuries, and fall injuries that then limited activity tentatively. They also noted that fallers were almost four times more likely than not to have poor balance confidence.

In examining falls risk factors among adults with knee osteoarthritis using a systematic approach, Manlapaz et al. [9] did show that impaired balance, muscle weakness, the presence of comorbidities, and increasing number of symptomatic joints are falls risk factors. However, the strength of evidence was rated as "conflicting" because of the inconsistency of the findings. Surprisingly, even though the authors found limited evidence for knee instability, impaired proprioception, and use of walking aids as falls determinants, no updated study has examined these possible valuable correlates. The role of disease severity or grade of disease another possibly highly salient falls predictor $[21,23]$ has also not been well studied, and remains controversial [24], even though Tasci Barbaz et al. [8] who studied 50 cases with knee osteoarthritis and 50 healthy controls, found that not only did the presence of primary knee osteoarthritis increase the risk of the individual for falling quite significantly, but those with higher disease rating scores were found to fall more than those with lower grade disease rating scores. Pain and function did not appear to influence the risk of falling in their patients, however, even though Amano and Suzuki [23] claim the ability to balance is a falls predictor among community-dwelling knee osteoarthritis cases, and pain has been identified as a falls predictor.

Moreover, the role of muscle strength and proprioception problems sufficient to explain the prevailing falls rate among osteoarthritis knee cases also remains elusive $[1,23]$, as does the role of comorbid health conditions [21], gender, and age [28, 29], plus the inability to walk $500 \mathrm{~m}$.

In addition, the pervasive use of self-reports to assess falls history [eg 21, 23, 30, 31], along with the frequent exclusion of osteoarthritis cases who might be cognitively challenged as well as at high risk for falls, implies conclusions reached on this basis must remain in question, pending more carefully designed and inclusive research. Additionally, efforts to examine the precise role of other potentially modifiable risk factors not highlighted in the literature, such as diabetic neuropathy, joint inflammation, assistive device use, footwear, sedatives, sleep issues, frailty, fatigue, and health beliefs about falling are clearly needed. As well, efforts to differentiate static from dynamic balance, which has not been studied to any degree in the knee osteoarthritis population, and its possible falls linkage, clearly undermines the ability to interpret the relative weight of the varied falls determinants that have been observed. Since almost a third of the current published studies on falls risk factors stem in knee osteoarthritis stem from a single source of information, and not from diverse samples of cases with well-defined and clearly established clinical and radiological knee osteoarthritis, or osteoarthritis subgroups, the ability to intervene to avert falls risk in knee osteoarthritis in a safe, goal directed, and timely way must surely await further study.

To improve the chances of identifying salient clinically relevant findings in future studies, not only is study design crucial, but approaches used to differentiate fallers from non fallers should be evaluated thoroughly.

Further topics that might be helpful in future efforts to extend this line of research in a more conclusive direction are those that might examine one or more of the following possible falls risk determinants in more detail than is presently the case:

- Functional, age, gender, nutritional, cognitive, and health status correlates.

- Medication intake, environmental, sleep, occupational, and activity factors. 
Current Knee Osteoarthritis and Non-Surgically Related Falls Injuries Studies: What Prevails, What is Needed, and Why

- Specific knee osteoarthritis correlates [22], such as pain, muscle fatigue and atrophy, falls fears and falls self-efficacy $[7,30]$.

In addition, to assist in the development of wellconstrued and possible efficacious preventive approaches, it appears that more concerted efforts devoted towards clearly differentiating high from low falls risk individuals [31] using samples that match the median age of most knee osteoarthritis cases who have either distinctive unilateral versus bilateral knee joint disease, that is not compounded by hip joint osteoarthritis will be helpful. Additional efforts to differentiate the relative impact of falls risk in early versus late stages of knee osteoarthritis, and in medial versus lateral compartment knee osteoarthritis are similarly highly indicated, as are the development of practical screening tools, along with ongoing falls diaries and electronic records.

Until then, despite a laudable number of published falls prevention approaches that have been advocated [eg., 17, 32-34], and possible article omission, a definitive basis for choosing one or more of these to apply in real world situations remains hard to justify. As well, even if deemed effective when studied in controlled conditions, some, for example community based falls preventive programs, personalized on site physical therapy interventions, and others may not be accessible or offered during the current COVID19 pandemic and beyond. At the same time, not all home based exercises or treatment plans are likely to be risk free, especially for those with one or more cardiovascular comorbid conditions and others, plus a history of buckling, poorly controlled pain, depression, visual impairments, and neuromuscular deficits. Indeed, simply advocating for unproven falls prevention strategies of one form or another, and applying these for purposes of decreasing falls risk among vulnerable in knee osteoarthritis cases [35] may not be at all safe in the case of inaccurate falls risk diagnoses, prognoses, perceptions and beliefs [36]. Moreover, efforts that may be indicated, but that do not include strategies to account for extrinsic falls determinants in the home, as well as community, and work environment, along with little attention to the individual's personal, cognitive, physical, and medical profile $[15,22]$ are also likely to fail to produce the desired effects.

\section{CONCLUSION}

Despite the immense clinical relevance of exploring this present topic, it is concluded there are too few well designed studies either in the current or the past data searches that have been conducted to warrant systematic appraisal.

Consequently, and in light of the indisputable fact that that falls are serious injuries that may prevail in sizeable numbers of knee osteoarthritis cases, and that falling can heighten knee osteoarthritis disability considerably, it is further concluded more welldesigned carefully construed research in this realm is highly desirable.

In particular, to overcome the manifold gaps and discordant findings in the literature, measures applied in a study by Levinger et al. [1] including the Short Form of the Physiological Profile Assessment used to assess falls risk, and which includes tests of vision, lower limb proprioception, knee extension strength, reaction time and postural sway is likely to prove especially valuable. Additional measures of physical activity, quality of life, fear of falls and disability and the clinical prediction rule developed by Amano et al. [23], along with the Comprehensive Geriatric Assessment tool [31] appear to hold great promise as well.

It is also concluded that more carefully construed prospective studies that explore an array of wellsupported knee osteoarthritis and falls risk correlates or deterministic factors, possible knee osteoarthritis sub-groups and a broad range of samples of adequate size will help to provide a sound contribution to the needed evidence base to underpin efficacious, safe, and cost-effective practical primary and secondary, falls preventive approaches.

\section{REFERENCES}

[1] Levinger P, Nagano H, Downie, C, Hayes A, Sanders KM, Cicuttini F, Begg R, et al. Biomechanical balance response during induced falls under dual task conditions in people with knee osteoarthritis. Gait Posture. 2016;48:106-112. doi:10.1016/j.gaitpost.2016.04.031 
Current Knee Osteoarthritis and Non-Surgically Related Falls Injuries Studies: What Prevails, What is Needed, and Why

[2] Pater ML, Rosenblatt NJ, Grabiner MD. Knee osteoarthritis negatively affects the recovery step following large forward-directed postural perturbations. J Biomech. 2016;49(7):11281133. doi:10.1016/j.jbiomech.2016.02.048

[3] van Tunen JAC, Dell'Isola A, Juhl C, Dekker J, Steultjens M, Thorlund JB, et al. Association of malalignment, muscular dysfunction, proprioception, laxity and abnormal joint loading with tibiofemoral knee osteoarthritis - a systematic review and meta-analysis. BMC Musculoskelet Disord. 2018;19(1):273. doi:10.1186/s12891018-2202-8

[4] Marks R. Osteoarthritis and falls: is there a link? J Aging Res Healthcare. 2020;3(2):1-13.

[5] Barbour KE, Sagawa N, Boudreau RM, Winger ME, Cauley JA, Nevitt MC, et al. Knee osteoarthritis and the risk of medically treated injurious falls among older adults: a community-based US cohort study. Arthritis Care Res. 2019;71(7):865874. doi: 10.1002/acr.23725.

[6] Smith TO, Higson E, Pearson M, Mansfield M. Is there an increased risk of falls and fractures in people with early diagnosed hip and knee osteoarthritis? Data from the Osteoarthritis Initiative. Int J Rheum Dis. 2018;21(6):11931201. doi: 10.1111/1756-185X.12871

[7] Kurtoglu P, Tastan S, Tunay S. How falls and fear of falling affect the performance of daily activities in individuals with knee osteoarthritis. Cntrl Eur J Nurs Midwif. 2020;11(1):25-33.

[8] Tasci Bozbas G, Sendur OF, Aydemir, AH. Primary knee osteoarthritis increases the risk of falling. J Back Musculoskelet Rehabil. 2017;30(4):785789. doi: 10.3233/BMR-150413.

[9] ManlapazDG,Sole G,Jayakaran P,ChappleCM. Risk factors for falls in adults with knee osteoarthritis: a systematic review. PMR. 2019;11(7);745-757. doi: 10.1002/pmrj.12066.

[10] di Laura Frattura G, Filardo, G, Giunchi D, Fusco A, Zaffagnini S, Candrian C.. Risk of falls in patients with knee osteoarthritis undergoing total knee arthroplasty: a systematic review and best evidence synthesis. J Orthop. 2018;15(3):903908. doi: 10.1016/j.jor.2018.08.026.

[11] Lo-Ciganic WH, Floden, L, Lee JK, Ashbeck EL, Zhou L, Chinthammit C, et al. Analgesic use and risk of recurrent falls in participants with or at risk of knee osteoarthritis: data from the Osteoarthritis Initiative. Osteoarthritis Cartilage. 2017;25(9):1390-1398. doi: 10.1016/j. joca.2017.03.017.

[12] Nevitt MC, Tolstykh I, Shakoor N, Nguyen US, Segal NA, Lewis C, et al: Multicenter Osteoarthritis Study Investigators. Symptoms of knee instability as risk factors for recurrent falls. Arthritis Care Res. 2016;68(8):1089-1097. doi: 10.1002/ acr.22811.

[13] Mat S, Tan PJ, Ng CT, Fadzli F, Rozalli FI, Khoo EM, et al. Mild joint symptoms are associated with lower risk of falls than asymptomatic individuals with radiological evidence of osteoarthritis. PLoS One. 2015;22:10(10). e0141368. doi: 10.1371/ journal.pone.0141368.

[14] van Schoor NM, Dennison E,Castell, MV, Cooper C, Edwards MH, Maggi S, et al: EPOSA research group. Clinical osteoarthritis of the hip and knee and fall risk: the role of low physical functioning and pain medication. Semin Arthritis Rheum. 2020;50(3):380-386. doi: 10.1016/j. semarthrit.2020.02.006.

[15] Ofori-Asenso R, Ackerman IN, Soh SE. Prevalence and correlates of falls in a middle-aged population with osteoarthritis: data from the Osteoarthritis Initiative. Health Soc Care Community. 2020 Jul 14. doi: 10.1111/hsc.13103.

[16] Aljehani MS, Crenshaw JR, Rubano JJ, Deliose SM, Zeni JA JR. Falling risk in patients with end-stage knee osteoarthritis. Clin Rheumatol. 2020 Jun 4. doi: 10.1007/s10067-020-05165-6.

[17] Anderson ML, Allen KD, Golightly YM, Arbeeva LS, Goode A, Huffman KM, et al. Fall risk and utilization of balance training for adults with symptomatic knee osteoarthritis: secondary analysis from a randomized clinical trial. J Geriatr Phys Ther. 2019;42(2):E39-E44. doi:10.1519/ JPT.0000000000000213 
Current Knee Osteoarthritis and Non-Surgically Related Falls Injuries Studies: What Prevails, What is Needed, and Why

[18] Hill KD, Wee E, Margelis S, Menz HB, Bartlett J, Bergman NR, et al. Falls in people prior to undergoing total hip or total knee replacement surgery: frequency and associated factors. J Clin Gerontol Geriatric. 2016;7(4):146-152.

[19] Melikoglu MA, Kul A. Fall risk and related factors in knee osteoarthritis. Ann Rheum Dis. 2017;76:1340-1341.

[20] Riddle DL, Golladay GJ. Preoperative risk factors for postoperative falls in persons undergoing hip or knee arthroplasty: a longitudinal study of data from the Osteoarthritis Initiative. Arch Phys Med Rehabil. 2018;99(5):967-972. doi: 10.1016/j. apmr.2017.12.030.

[21] Mat S, Ng CT, Fadzil F, Tan MP. The mediating role of psychological symptoms on falls risk among older adults with osteoarthritis. Clin Interv Aging. 2017;12:2025-2032

[22] Soh SE, Barker, AL, Ackerman INl. Applying the International Classification of Functioning, Disability and Health framework to determine the predictors of falls and fractures in people with osteoarthritis or at high risk of developing osteoarthritis: data from the Osteoarthritis Initiative. BMC Musculoskelet Disord. 2020;21(1):138.

[23] Amano T, Suzuki N. Derivation of a clinical prediction rule to determine fall risk in community-dwelling individuals with knee osteoarthritis: a cross-sectional study. Arch Osteoporos. 2019;14(1):90.

[24] Ng CT, Tan MP. Osteoarthritis and falls in the older person. Age Ageing. 2013; 42(5):56156-6. doi: 10.1093/ageing/aft070.

[25] Riddle DL, Golladay GJ.Alongitudinal comparative study of falls in persons with knee arthroplasty and persons with or at high risk for knee osteoarthritis. Age Ageing. 2016; 45(6):794-800. doi: 10.1093/ageing/afw126.

[26] Byun M, Kim J, Kim M. Physical and psychological factorsaffectingfallsinolderpatientswitharthritis. Int J Environ Res Public Health. 2020;17(3):1098. doi: 10.3390/ijerph17031098.
[27] Tsonga T, Michalopoulou M, Kapetanakis S, Giovannopoulou E, Malliou P, Godolias G, et al. Reduction of falls and factors affecting falls a year after total knee arthroplasty in elderly patients with severe knee osteoarthritis. Open Orthop J. 2016, 10, 522-531. doi: $10.2174 / 1874325001610010522$.

[28] Iijima H, Shimoura K, Aoyama T, Takahashi M. Low back pain as a risk factor for recurrent falls in people with knee osteoarthritis. Arthritis Care Res. 2020, Jan 7. doi: 10.1002/acr.24136. 31909877.

[29] Teder-Braschinsky A, Märtson A, Rosenthal M, Taba P. Parkinson's disease and symptomatic osteoarthritis are independent risk factors of falls in the elderly. Clin Med Insights Arthritis Musculoskelet Disord. 2019; 12; 1179544119884936. doi: $10.1177 / 1179544119884936$.

[30] Mat S, Ng CT, Tan MP. Influence of hip and knee osteoarthritis on dynamic postural control parameters among older fallers. J Rehabil Med. 2017;49(3);258-263. doi: 10.2340/165019772202.

[31] Veronese N, Siri G, Cella A, Maggi S, Maggi S, Zigoura E, Puntoni M, et al. The Multidimensional Prognostic Index predicts falls in older people: an 8-year longitudinal cohort study of the Osteoarthritis Initiative. J Am Med Dir Assoc. 2020;2(5):669-674.

[32] Mat S, Ng CT, Tan PJ, Ramli N, Fadzli F, Rozalli FI, et al. Effect of modified Otago exercises on postural balance, fear of falling, and fall risk in older fallers with knee osteoarthritis and impaired gait and balance: a secondary analysis. PMR. 2018;10(3);254-262. doi:10.1016/j. pmrj.2017.08.405

[33] Hou M, Wang X, Yu J, Fu S, Yang F, Li Z, et al. The effect of electroacupuncture on dynamic balance during stair climbing for elderly patients with knee osteoarthritis. Evid Based Complement Alternat Med. 2020;2020,3563584.

[34] Foucher KC, Pater ML, Grabiner MD. Taskspecific perturbation training improves the 
Current Knee Osteoarthritis and Non-Surgically Related Falls Injuries Studies: What Prevails, What is Needed, and Why

recovery stepping responses by women with knee osteoarthritis following laboratoryinduced trips. J Orthop Res. 2020;38(3):663-669. doi:10.1002/jor.24505

[35] Khan SJ, Khan SS, Usman J, Abu Osman NA. Combined effects of knee brace, laterally wedged insoles, andtoe-outgaitonkneeadductionmoment andfall riskinmoderatemedialkneeosteoarthritis patients. Prosthet Orthot Int. 2019;43(2):148157. doi:10.1177/0309364618796849

[36] Tsindos T, Ayton D, Soh SE, Ackerman IN. Perceptions of falls risk and falls prevention among people with osteoarthritis. Disabil Rehabil. 2020;Aug 18,1-8.

Citation: Ray Marks. Current Knee Osteoarthritis and Non-Surgically Related Falls Injuries Studies: What Prevails, What is Needed, and Why. Open Journal of Geriatrics. 2020; 3(2): 22-34.

Copyright: (c) 2020 Ray Marks. This is an open access article distributed under the Creative Commons Attribution License, which permits unrestricted use, distribution, and reproduction in any medium, provided the original work is properly cited. 